\title{
Detection and Adaptation in Parasitic Angiosperm Host Selection
}

\author{
Lizhi Liang1*, Yue Liu1* ${ }^{*}$ Jenil Jariwala², David G. Lynn"\#, Andrew G. Palmer# \\ ${ }^{1}$ Departments of Chemistry and Biology, Emory University, Atlanta, USA \\ ${ }^{2}$ Department of Biological Sciences, Florida Institute of Technology, Melbourne, USA \\ Email: "dlynn2@emory.edu, \#apalmer@fit.edu
}

Received 6 February 2016; accepted 19 June 2016; published 22 June 2016

Copyright (C) 2016 by authors and Scientific Research Publishing Inc.

This work is licensed under the Creative Commons Attribution International License (CC BY).

http://creativecommons.org/licenses/by/4.0/

(c) (i) Open Access

\begin{abstract}
Developmental transitions in some parasitic angiosperms are tied directly to host-derived chemical cues (xenognosins). The obligate hemi-parasite Striga asiatica, initiates the root apical meristem population (germination), development of the host attachment organ (the haustorium), and shoot apical meristem initiation (seed coat shedding) in response to specific xengonosins. These checkpoints synchronize spatial and temporal tissue development. We have now exploited the external control over these developmental transitions to trace functional expression in haustorial organogenesis. Genes associated with phytohormone regulation, metabolism, vascular tissue development, and reactive oxygen species (ROS) production identified in this study suggest an elaborate and global response closely tied to plant defense and redox chemistry that may also be components of a more general quorum sensing-type mechanism in plants.
\end{abstract}

\section{Keywords}

Parasitic Plants, Semagenesis, Parasitic Evolution, Xenognosis, Host Detection, Quorum Sensing

\section{Introduction}

While many adaptive or learned strategies have been acquired through biological evolution, nowhere are the learning processes more acute or dynamic than at mutualistic interfaces [1]. The constant and rapidly changing evolutionary tensions between intimately associated organisms may be most developmentally and metabolically dynamic in the sessile parasitic plants where chemical and tactile cues direct lifecycle phases [2]-[4]. The host-derived cues that mediate both acute and chronic developmental decision-making events are known as xe-

\footnotetext{
*Authors contributed equally to this work.

${ }^{\#}$ Corresponding author.
} 
nognosins, from the Greek words for "other" (xenos) and "knowledge" (gnosis).

Studies on Striga asiatica, an obligate hemi-parasitic angiosperm commonly known as witchweed, have defined the chemistry underlying host/parasite transition strategies in this noxious weed. Distinct classes of xenognosins provide the necessary and sufficient stimulus to initiate at least three separate developmental transitions, each of which is crucial to the successful development of the parasite [3]-[5] (Figure 1). Seeds of S. asiatica can remain viable under soil conditions for up to twenty years, germinating only in the presence of an SXSg (Sorghum Xenognosin for Striga germination) which includes strigolactones and/or dihydrosorgoleone derived from the roots of prospective host plants, including agriculturally important crops like maize and sorghum (Figure 1(a)) [6] [7]. Subsequent development of the host attachment organ, the haustorium, recommits the root apical meristem in a process known as semagenesis [8]-[10]. Reactive oxygen species (ROS) are actively exuded at the parasite root tip such that contact with host cell walls oxidatively liberates $p$-benzoquinone (pBQ) products. These $\mathrm{pBQs}$ are necessary and sufficient to initiate haustorial development; arrest of vegetative growth, induction of radial swelling of the root tip, and initiation of the ectopic root (haustorial) hairs (Figure 1(b)). Given the limited resources of the parasite for vegetative growth (3-5d), this process, which takes about $24 \mathrm{~h}$, prevents premature commitment. Following attachment, additional xenognosins appear necessary to initiate the cells of the shoot apical meristem (SAM). While specific endogenous factors that initiate this transition have yet to be defined formally, the exogenous addition of cytokinins (Figure 1(c)) can initiate SAM development [11]. Endogenous hormones derived by tapping the host vascular system [12] may allow the plant to complete its lifecycle, transitioning back to vegetative growth to reach seed set and, ultimately, senescence (Figure 1(d) \& Figure 1(e)).

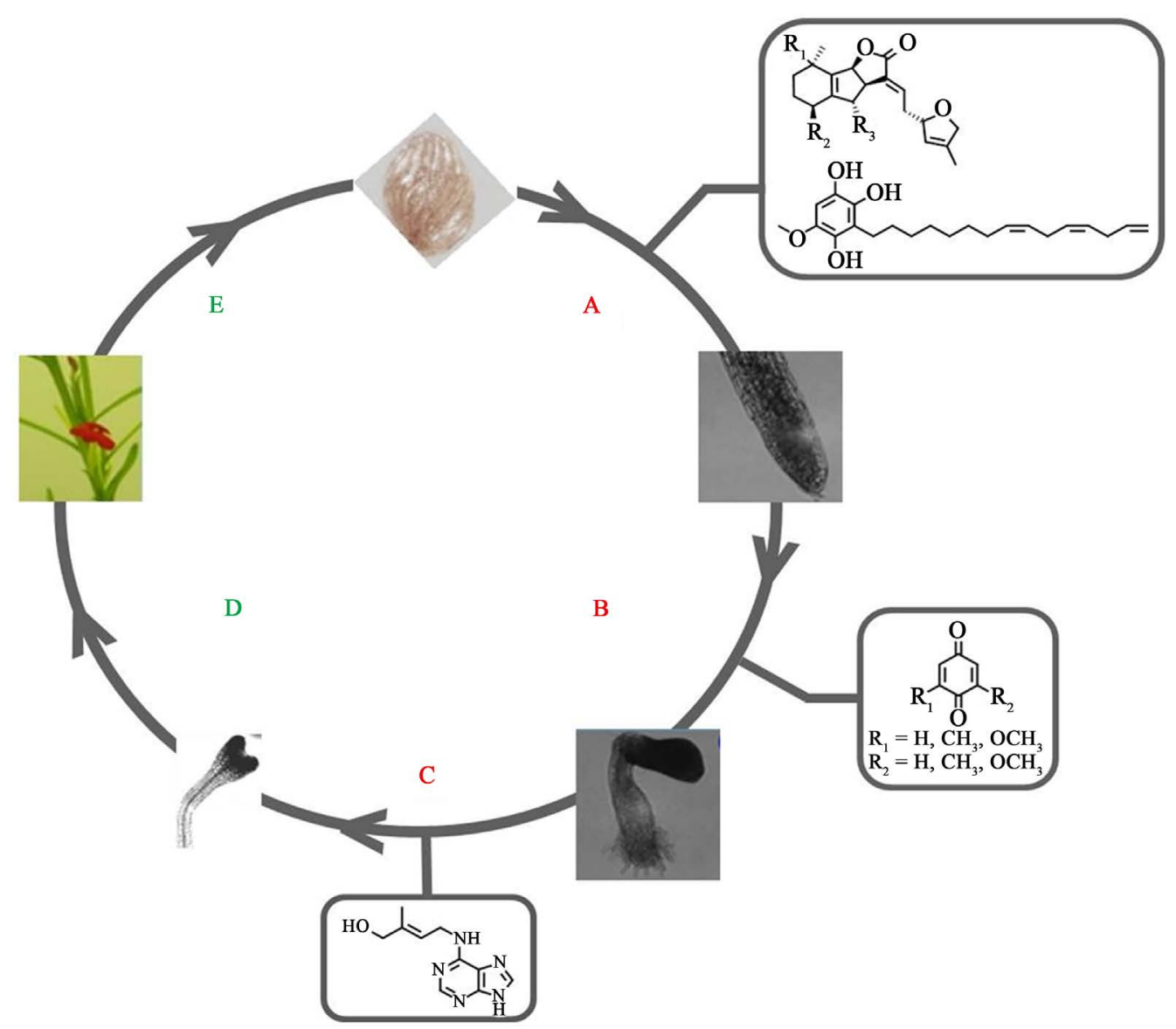

Figure 1. The life-cycle of $S$. asiatica is divided into stages that are either dependent ((a)-(c), red letters) or independent ((d) and (e), green letters) of xenognosins: (a) germination is initiated by strigolactones or SXSg; (b) haustorial organogenesis by p-benzoquinones; (c) shoot apical meristem development by cytokinins; (d) \& (e) Flowering, seed set, and seed dispersal are host independent. 
Many of these xenognosins and their analogues are now readily available, so these transitions can be easily and effectively managed under laboratory conditions. Most importantly, these developmental transitions are so highly synchronized across the population that it becomes possible to explore the molecular elements associated with surmounting the checkpoints on development. Not only will an analysis of the molecular events inform downstream regulatory and functional elements associated with specific plant developmental transitions [9] [13] [14] but the mechanisms of xenognosin regulation and how these cues impact existing machinery will provide insight into the functional evolution and successful strategies of host and parasite adaptation.

Here we combine this xenognosin-directed control over development with transcriptional profiling to identify specific elements associated with the commitment to haustorial organogenesis in $S$. asiatica. The identified genes suggest that semagenesis and haustorial organogenesis are connected to a quorum sensing-like process which facilities the synthesis and integration of biotic signals derived from neighboring plants to manage general growth and development. We also present evidence in support of existing models that the functional origins of these processes lie in the existing defense strategies of plants, most notably the oxidative burst response [15].

\section{Materials and Methods}

CM- $\mathrm{H}_{2}$ DCFDA was purchased from Molecular Probes (Carlsbad, CA). Murashige and Skoog (MS) media was purchased from Caisson Labs (North Logan, UT). All other chemicals were obtained from Sigma Aldrich (St. Louis, MO). Columbia-0 (Col-0) wild-type Arabidopsis thaliana seeds were purchased from Lehle Seeds (Round Rock, TX). Striga asiatica seeds were obtained from the U.S. Department of Agriculture (Beltsville, $\mathrm{MD})$ and all experiments were conducted under quarantine conditions for noxious plants. These experiments were conducted under the auspices of the USDA quarantine license awarded to Emory University.

\subsection{S. asiatica Germination and Haustorium Development}

Seeds of Striga asiatica were pre-treated and germinated as previously described using $10^{-9} \mathrm{M}$ Strigol [2]. Germination was evaluated after $36-48$ hours and at this point experiments were initiated. Assays for haustorium development were performed as previously described [9].

\subsection{S. asiatica Plant Cultures}

Plant cultures were obtained by transferring one day old seedlings of Striga asiatica to Magenta boxes containing 1xMS medium supplemented with either: $1 \mathrm{mg} / \mathrm{L}$ 6-BA and $0.1 \mathrm{mg} / \mathrm{L}$ IAA or $1 \mathrm{mg} / \mathrm{L}$ 6-BA and $0.5 \mathrm{mg} / \mathrm{L}$ IAA. Seedlings were grown at $23^{\circ} \mathrm{C}$ with a $16 \mathrm{~h}$ photoperiod/day. Regenerated shoots were visible after one week, and the resulting Striga plants typically flowered within 4 - 6 weeks under these conditions.

\subsection{SSH Libraries of $S$, asiatica Expression in Response to DMBQ}

Forward and reverse subtracted cDNA libraries were generated from mRNA extracted from day-old S. asiatica seedlings either treated with $10 \mu \mathrm{M}$ DMBQ for $6 \mathrm{~h}$ (pre-haustorium formation) or untreated. Suppression Subtractive Hybridization (SSH) was performed using a Clontech SSH Kit. These two cDNA libraries were used as both TESTER and DRIVER to generate a complete library of targets both up and down regulated by DMBQ exposure. Sequenced hits were identified by BLAST analysis and added to the NCBI database. These hits were utilized as the source of primers for subsequent relative transcription-PCR analyses at subsequent time points in haustorial organogenesis using actin as an internal standard for amplification.

\subsection{NADPH Oxidase Cloning}

Total RNA was extracted from germinated seedlings of S. asiatica with the RNeasy Plant Mini Kit (Qiagen). Integrity of the isolation was analyzed by electrophoresis in a $8 \%$ formaldehyde $/ .5 \%$ agarose gel. cDNA was generated using Superscript ${ }^{\mathrm{TM}}$ III Transcriptase (Invitrogen) at $50^{\circ} \mathrm{C}$. Based on the conserved NADPH and FAD binding domains of the Respiratory burst oxidases from Arabidopsis thaliana (RbohA) and Nicotiana tabacum (NtRbohA), several degenerate primers were prepared and investigated. For example, the primer pair forward 5'-GGCAYCCITTYTCWATYACITC-3' and reverse: 5'-GGHGTIGCWCCDATICCNARWC-3' as well as several other degenerate primer pairs successfully cloned genes from 1.5-day-old Striga seedling cDNA. PCR

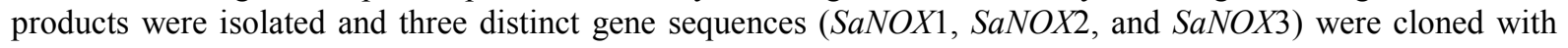


the help of TOPO TA Cloning Kit (Invitrogen). Whole cDNA sequences of the three genes were obtained with the help of SMART ${ }^{\mathrm{TM}}$ RACE cDNA Amplification Kit (Clontech). Based on cDNA sequences, three genomic sequences were obtained from $S$. asiatica genomic DNA, extracted using the DNeasy Plant Mini Kit (Qiagen). The promoter region for each putative SaNOX homologue was identified by the thermal asymmetric interlaced (TAIL)-PCR method [16].

\subsection{Evaluating Localization and Regulation of SaNOX Expression}

To analyze the expression pattern of these genes, RT-PCR was performed on 3 distinct sets of tissues: 1) roots, 2) shoots, and 3) leaves and flowers. RNA and cDNA were obtained as described above. In order to exclude genomic DNA contamination, RNA was pretreated with DNase. The RT-PCR studies utilized two primers for each gene (SaNOX1-3) and two primers for actin as an internal standard. $S a N O X 1$, 2, and 3 expression levels were evaluated by 28,30 , and 30 cycles respectively with an annealing temperature of $58^{\circ} \mathrm{C}$. The RT-PCR experiments for each gene were repeated in triplicate with different cDNA samples. Gene specific primers used in RT-PCR were: $S a N O X 1$ reverse: 5'-ctgcaccggacgatgactatcttagc-3'; forward: 5'-ctgctatatcatccataacgcctttg-3' or reverse: 5'-cagatcttccgagggacgaatccgtaaaat-3'; forward: 5'-gccatgttgaatttgacggtctcggcag-3'. SaNOX2 reverse:

5'-ttgcctaagccatttgaccgcctca-3'; forward: 5'-cctaactgccttatgtgaatgctgagg-3'. SaNOX3 reverse:

5'-cgagctattggcatttcgtgttgagc-3'; forward: 5'-ccttgtggctttgacatgtgcagagcc-3'. Actin reverse:

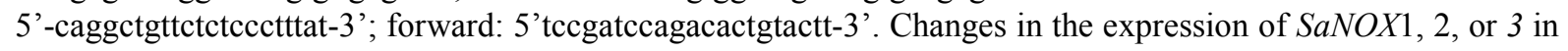
responses to quinone treatments were evaluated in a similar manner. For Northern analysis, Total RNA from specific Striga tissue was extracted as above. Approximately, $10 \mu \mathrm{g}$ of each RNA sample was transferred to a nylon membrane, and probed with the $\mathrm{P}^{32}$ labeled cDNA sequence for SaNOX1. Samples are washed 3 times and exposed to X-ray film (Kodak).

\subsection{Cloning SaNOX Promoters and Transient Arabidopsis Transformation}

Isolated promoters for SaNOX1-3 were cut by SalI and XbaI, and ligated into the PBI101 vector to generate the promoter-directed $\beta$-glucuronidase (GUS) reporters. Transient expression of the reporter constructs in Arabidopsis thaliana Columbia-0 (wildtype) seedlings was facilitated via vacuum infiltration of Agrobacterium tumefaciens GV3101 strains bearing the appropriate promoter:reporter construct. Transformed seedlings were selected on 1xMS plates with Kanamycin $(50 \mu \mathrm{g} / \mathrm{ml})$ and subjected to GUS staining [17].

\subsection{GUS Assay}

Arabidopsis transformants are vacuum infiltrated for 5 minutes in the staining solution (50 mM sodium phos-

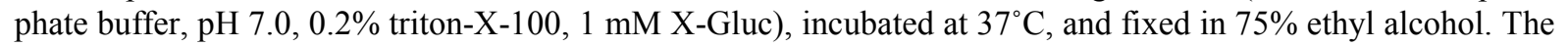
pictures were taken with a Canon digital camera.

\section{Results}

\subsection{Developmental Phases Can Be Synchronized by Xenognosins in S, asiatica Seedlings}

Our approach depends on the synchronized population-wide response of $S$. asiatica to xenognosin exposure. We therefore began by considering exposure times and conditions for each of the xenognosin-mediated developmental transitions: root apical meristem initiation (germination), haustorial organogenesis, and shoot apical meristem (SAM) initiation. Previous studies established that a $6 \mathrm{~h}$ exposure to sub-micromolar concentrations of SXSg results in near quantitative germination of $S$. asiatica [6] [11]. Similarly a 6 h exposure to $10 \mu \mathrm{M} 2,6$-dimethoxy-p-benzoquinone (DMBQ), a previously established haustorial inducer, induces population-wide terminal commitment to haustorial organogenesis [13].

A specific xenognosin for shoot apical meristem initiation has yet to be identified. However, exogenous cytokinins have been shown to induce germination, haustorial organogenesis, and shoot apical meristem development in S. asiatica [11]. In these prior studies, the arrested dormancy of the shoot apical meristem was observed by the shedding of the seed coat, which we used as a simple reporter. In $S$. asiatica seedlings in which haustoria were pre-formed, a $4 \mathrm{~h}$ exposure to $10 \mu \mathrm{M}$ trans-zeatin resulted in 50\% seed coat shedding $\left(\mathrm{t}_{1 / 2}\right)$ within 24 hours (Figure 2). This effect was not isolated to trans-zeatin as $10 \mu \mathrm{M}$ treatments with 6-benzyl adenine (6-BA) or kinetin also induced population-wide seed coat shedding with $\mathrm{t}_{1 / 2}$ exposures of $6 \mathrm{~h}$ and $10 \mathrm{~h}$, respectively. 


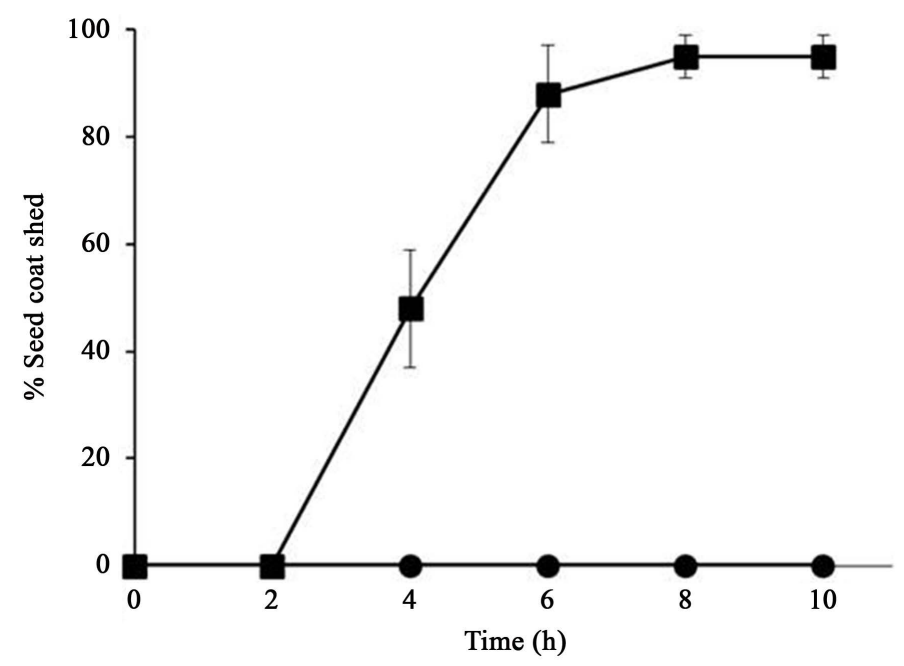

Figure 2. Cytokinins induce shoot apical meristem development in S. asiatica. Pre-haustoria are formed on seedlings of $S$. asiatica (See Methods). These seedlings are rinsed in triplicate then placed in buffer either $(\boldsymbol{\square})$ with or $(\bullet)$ without $10 \mu \mathrm{M}$ trans-zeatin at room temperature. Seedlings are scored for shedding of the seed coat, as an indicator of SAM initiation, at the indicated time point. Results are the average of three trials with error equal to $+/-$ the standard deviation of the mean. $n=50$ seedlings.

\subsection{Difference Library Construction and Analysis of Regulated Genes}

Knowing the exposure time required for developmental commitment allowed us to optimize library construction. Suppression subtractive hybridization (SSH) permits the identification of differential gene expression between two populations and has been exploited for studies ranging from metagenomic analyses to the responses of a single individual to exogenously added molecular signals [18] [19]. In this process, mRNA is isolated from the two populations to be compared and reverse transcribed into cDNA carrying distinct adaptor sequences. dsDNA hybrids formed between members of the two libraries are removed, identifying the differential expression of specific genes.

The phenotypes that score for the initiation of germination and apical meristem initiation (seed coat shedding) provide simple yes/no readouts. The timing of the various events during haustorial organogenesis can be divided into 3 distinct stages: (I) pre-commitment $(<2 \mathrm{~h})$, (II) transitioning $(2-6 \mathrm{~h})$, and (III) post-commitment $(8-24$ h). Stage II is further characterized by an arrest in root elongation and Stage III by (III.a) early commitment/radial swelling, (III.b) haustorial hair initiation (16 h) and (III.c) complete organogenesis. These transitions provide well-defined intermediate time points for library construction, offering improved resolution of the changes in gene expression associated with this developmental transition. We therefore selected haustorial organogenesis as the first xenognosin-regulated transition for evaluation by SSH.

Focusing on Stage II, when mRNA is extracted from day-old S. asiatica seedlings treated with $10 \mu \mathrm{M}$ DMBQ for $6 \mathrm{~h}$ and compared with untreated seedlings, 34 unique hits are identified. Estimated fold-change analysis of these products via relative transcription-Polymerase Chain Reaction (rt-PCR), with actin as an internal standard, indicated that 5 of these products show $<2$-fold change in expression and are therefore excluded from further analysis. Initial assignments of the remaining 29 products is accomplished via BLAST analysis utilizing the NCBI database, and organized into separate groups based on their proposed functions: 1) Cell wall expansion and vascular tissue development; 2) plant defense; 3) nutrient metabolism and transport; and 4) hormone regulation (Table 1). In addition, two previously identified expansins of $S$. asiatica [14] as well as a homolog of the quinone oxidoreductase QR2 from Triphysaria versicolor [20], a facultative root parasite in the Orobanche (broomrape) family, are identified in this library. The observed changes in expression appear specific to xenognostic quinones as the non-inducing di-tert-butyl-benzoquinone has no discernable effect on gene expression and tetrafluorobenzoquinone (TFBQ), a reversible inhibitor of haustorium development, blocks the differential expression mediated by DMBQ [14].

The differential expression of these genes over the $24 \mathrm{~h}$ period of haustorium development, relative to un- 
Table 1. Sequences obtained from the DMBQ-induced haustorium library.

\begin{tabular}{|c|c|c|c|c|c|c|c|c|c|}
\hline \multirow[b]{2}{*}{ ID } & \multirow[b]{2}{*}{ NCBI ID ${ }^{a}$} & \multirow{2}{*}{$\begin{array}{l}\text { Matching } \\
\text { sequence }^{\mathrm{b}}\end{array}$} & \multirow[b]{2}{*}{ E-value } & \multirow[b]{2}{*}{ Putative function } & \multicolumn{5}{|c|}{ Fold change in expression $(\mathbf{h})^{\mathrm{c}, \mathrm{d}}$} \\
\hline & & & & & $\begin{array}{c}0.5 \\
\text { I }\end{array}$ & $\begin{array}{c}2 \\
\text { II }\end{array}$ & $\begin{array}{l}6^{\mathrm{e}} \\
\mathrm{II}\end{array}$ & $\begin{array}{c}16 \\
\text { III }^{\mathrm{b}}\end{array}$ & $\begin{array}{c}24 \\
\text { III }^{\mathrm{c}}\end{array}$ \\
\hline \multicolumn{10}{|c|}{ Cell wall Expansion and vascular tissue development } \\
\hline 1 & DQ442395 & AY144594 & $6.00 \mathrm{E}-119$ & Xyloglucan endotransglycosylase & 1 & 1.5 & 3 & 2.5 & 3 \\
\hline 2 & DQ442401 & AF184233 & $1.00 \mathrm{E}-93$ & Expansin & 3 & 3 & 3 & 3 & 3 \\
\hline 3 & AF291657 & AF512542 & $2.00 \mathrm{E}-87$ & Expansin & 2 & 2 & 3 & 2 & 2 \\
\hline 4 & AF291658 & AB093031 & $2.00 \mathrm{E}-85$ & Expansin & 2.5 & 2.5 & 2.5 & 2.5 & 2 \\
\hline 5 & DQ442392 & AJ223969 & $9.00 \mathrm{E}-102$ & Elongation factor 1 & 1 & 1 & -10 & -10 & -10 \\
\hline 6 & DQ445120 & AY231146 & $5.00 \mathrm{E}-103$ & Alpha-tubulin & 1 & -2 & -6 & -5 & -5 \\
\hline 7 & DQ445123 & $\mathrm{AB} 084381$ & $5.00 \mathrm{E}-64$ & Homeobox leucine-zipper & 1.5 & 2.5 & 3 & 3 & 2.5 \\
\hline 8 & DQ431680 & XM_482629 & $4.00 \mathrm{E}-39$ & Putative chorismate mutase & 4 & 2.5 & 2.5 & 2.5 & 2 \\
\hline 9 & DQ445134 & NM_116339 & $5.00 \mathrm{E}-68$ & Unknown & 1 & -8 & -10 & -8 & -8 \\
\hline \multicolumn{10}{|c|}{ Plant defense responses } \\
\hline 10 & DQ431679 & XM_02532771 & $2.00 \mathrm{e}-114$ & Respiratory burst oxidase & -2.5 & -5 & -5 & -10 & -10 \\
\hline 11 & DQ442383 & AB050849 & $6.00 \mathrm{E}-68$ & Calmodulin & 1 & 1 & 6 & 5.5 & 5.5 \\
\hline 12 & DQ442394 & NM_180054 & $2.00 \mathrm{E}-27$ & Calmodulin binding & 3 & 3 & 3 & 3 & 2.5 \\
\hline 13 & DQ442396 & AY206407 & $2.00 \mathrm{E}-71$ & Ascorbate peroxidase & -5 & -10 & -10 & -8 & -8 \\
\hline 14 & DQ442387 & ABA93963 & $2.00 \mathrm{E}-62$ & GDSL lipase & 1.5 & 1 & -5 & -5 & -6 \\
\hline 15 & DQ445121 & NM_123583 & $1.00 \mathrm{E}-114$ & Peroxidase & -8 & -8 & -9 & -8 & -8 \\
\hline 16 & DQ442385 & AF242491 & $1.00 \mathrm{E}-67$ & PCBER reductase & 1 & -8 & -9 & -9 & -9 \\
\hline 17 & DQ442405 & AF304462 & $1.00 \mathrm{E}-84$ & Quinone-oxidoreductase QR2 & 7.5 & 7.5 & 8.5 & 8.5 & 8.5 \\
\hline \multicolumn{10}{|c|}{ Nutrition, metabolism, and transportation } \\
\hline 18 & DQ442379 & AJ278765 & $1.00 \mathrm{E}-62$ & Sugar transporter & 2 & 2 & 3 & 2 & 2 \\
\hline 19 & DQ445131 & NM_129389 & $2.00 \mathrm{E}-27$ & Antiporter/drug transporter & 4.5 & 4.5 & 6.5 & 6 & 6 \\
\hline 20 & DQ442390 & AK176585 & $1.00 \mathrm{E}-32$ & Carboxypeptidase & 1.5 & 4.5 & 4.5 & 5 & 5 \\
\hline 21 & DQ445132 & AJ849375 & $5.00 \mathrm{E}-73$ & Carbonic anhydrase & 2.5 & 2.5 & 2.5 & 2.5 & 2.5 \\
\hline 22 & DQ445137 & $\mathrm{AB} 183015$ & $1.00 \mathrm{E}-96$ & Zinc-binding dehydrogenase & 1 & 2.5 & 2.5 & 2.5 & 2.5 \\
\hline 23 & DQ445126 & AC021199 & $2.00 \mathrm{E}-73$ & Hydroxymethyltransferase & ND & 1 & 4 & 4 & 4 \\
\hline 24 & DQ445129 & AY226830 & $3.00 \mathrm{E}-18$ & Desacetoxyvindoline 4-hydroxylase & 3 & 3.5 & 3.5 & 3.5 & 3.5 \\
\hline 25 & DQ442381 & NM_119911 & $1.00 \mathrm{E}-92$ & Catalytic hydrolase & 1.0 & -8 & -8 & -8 & -7 \\
\hline \multicolumn{10}{|c|}{ Hormonal pathways } \\
\hline 26 & DQ431687 & AF534888 & $7.00 \mathrm{e}-54$ & Type-A RR & 1 & 2.5 & 3 & ND & ND \\
\hline 27 & DQ431686 & NM_115563 & $6.00 \mathrm{e}-59$ & Type-A RR & 1 & 5 & 5 & ND & ND \\
\hline 28 & DQ442403 & AY090553 & $4.00 \mathrm{E}-100$ & Auxin-regulated protein & 1 & 1 & 3 & 3 & 3 \\
\hline 29 & DQ442404 & AF373100 & $2.00 \mathrm{E}-86$ & Auxin-regulated protein & 3.5 & 3.5 & 3.5 & 3.5 & 3.5 \\
\hline
\end{tabular}

${ }^{a}$ : NCBI ID of deposited full-length sequence determined from cDNA; ${ }^{b}$ : Matching sequence identified through BLAST analysis; ${ }^{c}:$ Time seeds were harvested for library construction; ${ }^{d}$ : Expression-levels are based on relative transcription PCR to untreated seedlings with actin used as internal standard to normalize results; ${ }^{\mathrm{e}}$ : Time point for initial SSH library construction. ND $=$ Not Determined. 
treated (DMBQ-free) seedlings of similar age by the same rt-PCR analysis method, is summarized in Table 1. Specifically, these results are categorized and discussed in terms of the individual developmental stages:

I. Pre-commitment $(0.5 \mathrm{~h})$. Of the 29 genes identified in our library, $12(40 \%)$ are differentially expressed within $0.5 \mathrm{~h}$ after DMBQ exposure. This group includes two known expansins (3 and 4) [14], as well as a newly identified expansin (2). Up-regulation of these proteins may be correlated with remodeling of the root tip. However, some of the most dramatic changes in expression at this early time point are associated with ROS production. This group includes the down regulation of an NADPH oxidase (10) as well as peroxidases $\mathbf{1 3}$ and $\mathbf{1 5}$. The significant up-regulation (>7-fold) of a QR2 homologue (17) is particularly noteworthy given previous studies in T. versicolor that implicate QR2 as a potential receptor for xenognostic $p$-benzoquinones [21].

Also apparent are changes in the expression of genes associated with metabolism and transport of nutrients as well as hormone regulation. A putative auxin regulatory protein, 29, supports phytohormone regulation early during haustorial organogenesis. A role for auxin at this early time point is also consistent with the arrest of root elongation observed upon DMBQ exposure prior to commitment. Phytohormone studies in T. versicolor have also implicated a role for auxin signaling in haustorial organogenesis [22]. As cytokinins induce haustorium development, the developmental transition may also be regulated by both of these often antagonistic hormones [11].

II. Transitioning $(2-6 \mathrm{~h})$. Differential regulation of the remaining $17(\approx 60 \%)$ genes in the library largely occurs throughout the period of commitment to haustorium development $(2-6 \mathrm{~h})$. The expansins $(\mathbf{2}-\mathbf{4})$ remain up regulated, while Elongation factor 1 (5) and $\alpha$-tubulin (6) are both significantly down regulated, suggesting some relationship between the rate of protein synthesis and microtubule assembly in regulating haustorium development [23] [24]. We note that $\alpha$-tubulin knockdowns in A. thaliana are characterized by radial expansion of the root tip, arrested root elongation, and ectopic root hair formation adopting a structure morphologically similar to the haustorium [23]. Regarding plant defense responses, the NADPH oxidase (10), peroxidases (13 and 15), and QR2 (17) remain differentially regulated throughout this period as well. Calmodulin (11) expression increases during this time period implicating $\mathrm{Ca}^{2+}$-mediated signaling events in commitment and/or development. Some genes associated with metabolism and transport of nutrients as well as hormone regulation (19, 21, 24, and 29) remains differentially regulated during this time period. Two cytokinin associated response regulators (26 and 27) are also upregulated during this period.

III. Post-commitment (16 - $24 \mathrm{~h}$ ). Finally, the rt-PCR assays of library members at 16 and 24h post-DMBQ exposure show no significant variation in the expression relative to the $6 \mathrm{~h}$ treatment. These results are consistent with the molecular elements required for haustorium development being largely in place after $6 \mathrm{~h}$, coupling expression to the clock for terminal commitment [13].

\subsection{Library Guided Identification of Genes for Semagenic ROS Production}

The connection to defense and wounding is the most dominant and striking feature of all three stages. ROS production is central to the semagenesis mechanism and likely an early and important element in the functional emergence of parasitic angiosperms. Production is tightly regulated by the presence of xenognostic quinines [9], which may be due to a reduction in the expression of a ROS-producing catalyst. Likely candidates for this catalyst in plants include xanthine oxidases [25], peroxidases [26], lipoxygenases [27], polyamine oxidases [28], mitochondrial NADH dehydrogenases [29], oxalate oxidases [30], and NADPH oxidases [31]-[33]. The SSH library identified two peroxidases (13 and 15) and one NADPH oxidase (10) down regulated by DMBQ exposure during pre-commitment $(0.5 \mathrm{~h}$, stages I) and transition $(2-6 \mathrm{~h}$, stage II).

Several possible inhibitors for ROS synthesis were evaluated including Salicylhydroxamic acid (SHAM), AEBCF, Apocynin, Phenylarsine oxide (PAO), Diphenylene iodonium (DPI), Oxypurinol, Allopurinol, Rotenone, MDL7257, and Nordihydroguaiartic acid [33]-[41]. Of these, only diphenylene iodonium (DPI) and phenylarsine oxide (PAO) inhibits ROS production in S. asiatica seedlings (Supplementary Figure S1), most consistent with a superoxide $\left(\mathrm{O}_{2}{ }^{-}\right)$generating NADPH oxidase (NOX), like 10, as the catalyst [31]-[33]. The putative Striga asiatica NADPH oxidase 1 (10) is referred to as $S a N O X 1$ for the remainder of the discussion.

Degenerate oligonucletoide primers for the conserved regions of NOX proteins successfully identified two additional putative NOX homologues: SaNOX2 and SaNOX3 (accession numbers DQ431678 and DQ431677) [42] [43]. Distinct promoter sites for each of these genes were obtained using thermal asymmetric interlaced polymerase chain reaction (TAIL-PCR) [16]. Exon-intron analyses of the full-length genomic sequences, as well 
as structural predictions based on the mRNA, are available in the Supplementary Information and summarized below (Supplementary Figures S2-S4).

NADPH oxidases in plants are often referred to as respiratory burst oxidase homologue (Rboh) proteins due to their initial discovery as the source of the oxidant in this immune response [42] [43]. Consistent with known Rboh proteins, analysis of the SaNOX1 sequence supports the presence of well-conserved structural features including (from $\mathrm{N} \rightarrow \mathrm{C}$ ): 1) $2 \mathrm{Ca}^{2+}$-binding EF-hand domains, 2) 6 transmembrane helices, 3) corresponding histidines for heme-binding on helices III and V, 4) an FAD-binding domain, and 5) an NADPH-binding domain [42] [43]. In contrast, SaNOX2 and SaNOX3 appear to be N-terminal truncations that begin in the loop between transmembrane helix I and II. All three proteins have distinct, homologous sequences with unique exon-intron patterns.

Northern blot and PCR-based expression analysis of SaNOX1-3 in S. asiatica plants grown in culture confirm SaNOX2 \& SaNOX3 are transcribed throughout the plant, while SaNOX1 expression is limited to the roots (Figure 3(a) and Figure 3(b)). In order to further refine SaNOX1-3 localization, Arabidopsis thaliana was employed as a heterologous host expression system. Transient expression via Agrobacterium-mediated vacuum infiltration was used to identify specific sites of SaNOX expression. SaNOX2::GUS and SaNOX3::GUS transformants accumulate stain throughout the plant (Figure 3(c) and Figure 3(d)) while in the SaNOX1::GUS staining is limited to the root tip (Figure 3(e) and Figure 3(f)), the corresponding site of ROS production in S. asiatica.

Prior to the commitment to haustorial organogenesis, the removal of $\mathrm{pBQs}$ restores semagenic ROS production [9], and as shown in Figure 4, the expression of SaNOX1 as well. Additional haustorial inducing pBQs, like the unsubstituted $p$-benzoquinone or methyl- $p \mathrm{BQ}$ also attenuate ROS production as well as SaNOX1 expression, further supporting a connection to semagenesis (data not shown).

(a)

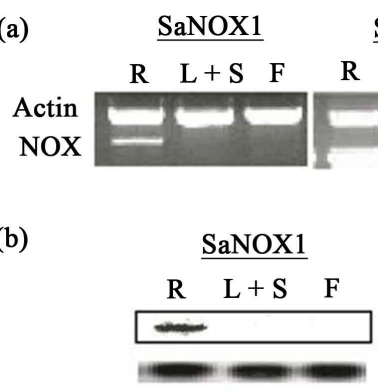

$18 \mathrm{~S}$ rRNA $\underline{\text { SaNOX3 }}$

$\frac{\mathrm{SaNOX} 2}{\mathrm{~L}+\mathrm{S} F \quad \mathrm{R} \quad \mathrm{L}+\mathrm{S} \text { F }}$

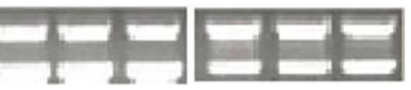

SaNOX3

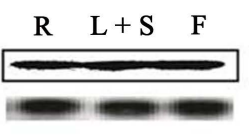

18S rRNA

(d)
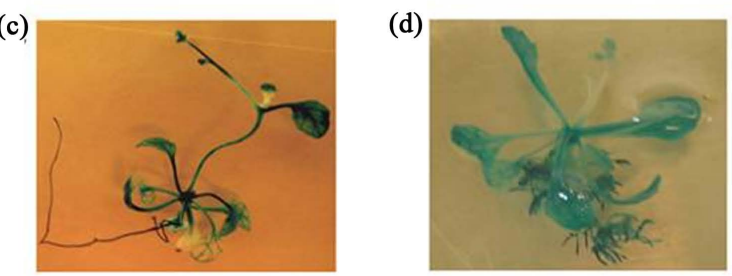

(e)

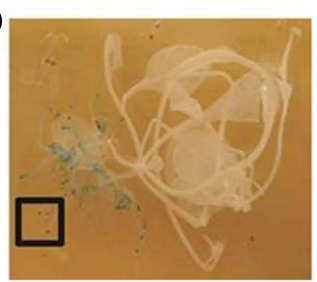

(f)

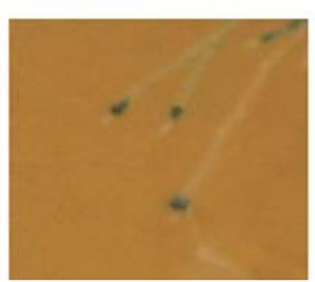

Figure 3. Tissue localization and expression of SaNOX1-3. Tissues harvested from germinated seedlings (root) or mature cultured $S$. asiatica plants were (a) screened for SaNOX1-3 localization of expression by relative transcription PCR using actin as a control; (b) Expression of $S a N O X 1$ and $S a N O X 3$ were confirmed by Northern analyses using 18s rRNA as a control. Lane labels are R: Root, L + S: Leaf + Stem; and F: Flower. (c)-(f) A. thaliana mutant lines expressing $\beta$-glucoronidase downstream of the promoters for SaNOX2 (c), SaNOX3 (d), and SaNOX1 (e) \& (f) were generated to establish expression localization of each product. 


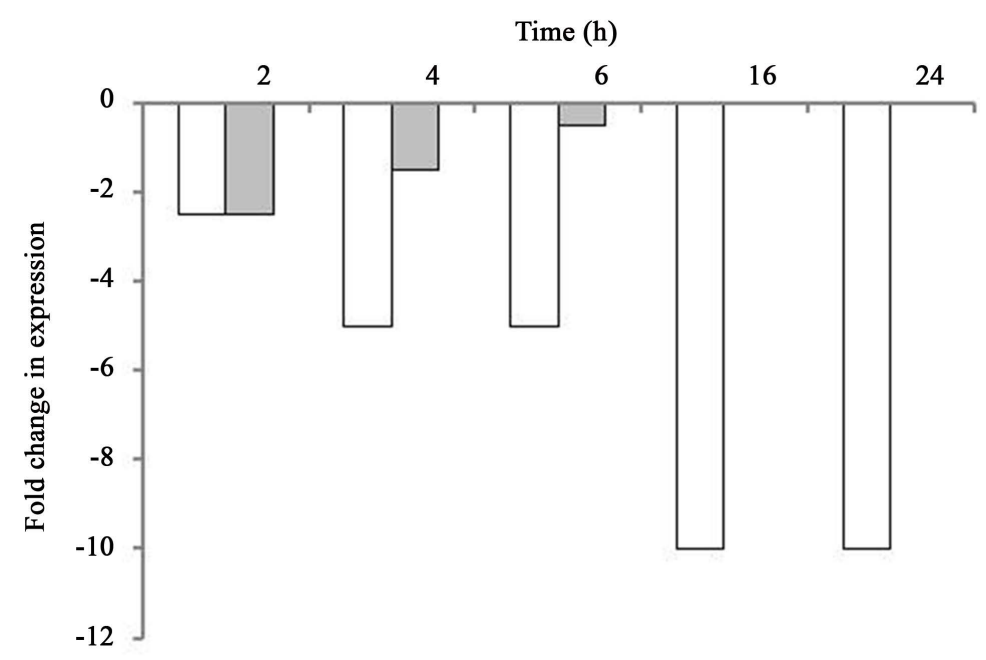

Figure 4. SaNOX1 expression is reversible prior to commitment to haustorial organogenesis. SaNOX1 expression was evaluated via RT-PCR at the indicated time points following the addition of $10 \mu \mathrm{M}$ DMBQ. After $2 \mathrm{~h}$ of DMBQ exposure seedlings were washed in triplicate and placed in either buffer (grey) or returned to a solution of $10 \mu \mathrm{M}$ DMBQ (white). Auxin was used as an internal standard for normalization.

\section{Conclusions}

The successful integration of a eukaryotic parasite with its host presents many of the same synchronization challenges faced during multicellular tissue development. The temporal and spatial control over cell fate defines tissue architecture, and the mechanisms underlying these precise responses appear to be similarly constrained between two distinct organisms. Defining the temporal and spatial organization of the chemistry that makes this control possible has significant practical and theoretical consequences for plant development as well as the adaptations necessary for both pathogenic and mutualistic symbioses.

Here we have focused our attention on the haustorium, the host attachment organ whose development is common across the various manifestations of the parasitic strategy in plants [44] [45]. In S. asiatica, as well as other parasitic plants, the detection of simple $p$-benzoquinones is both necessary and sufficient to mobilize the genetic elements necessary for the rapid functional transition to the haustorium. Our initial differential expression library identified 29 genes that were regulated during commitment to haustorial organogenesis. These genes fall into the general categories of cell wall expansion and vascular tissue development, nutrient metabolism and transport, hormone regulation, and cellular defense (Table 1).

The haustorium provides the vascular conduit between host and parasite in the parasitic plants, and its development begins with the radial swelling and ectopic root hair formation necessary for host attachment. The genes associated with cell wall expansion (e.g., expansins) as well as vascularization (e.g., chorismate mutase) are reasonable candidates for differential expression during haustorial organogenesis. The down-regulation of $\alpha$ tubulin expression is of particular interest given that $A$. thaliana knockdowns of this protein give root phenotypes similar to that observed in haustorial organogenesis: radial expansion of the root tip, arrested root elongation, and ectopic root hair formation [23] [24]. The general up-regulations of genes associated with nutrient metabolism and transport are consistent with the principal function of the haustorium: tapping host resources. The regulated flux of auxins and cytokinins is probably the most expected of a developmental transition and consistent with previous studies of haustorial organogenesis [22].

Conversely, the changes in defense gene expression seem contradictory. On one hand, the grafting of two tissues through the haustorium must involve the regulation of xenognostic processes, while at the same time constitutive ROS production in the tissue undergoing haustorial organogenesis is central to the chemical mechanism of semagenesis. The SSH library and subsequent PCR analyses confirmed the down regulation of two putative sources of semagenic ROS, a peroxidase (15) and an NADPH oxidase (SaNOXI) (10). Small molecule inhibitors further implicated the NADPH oxidase (SaNOX1) as the source of ROS at the root tip that was regulated in response to DMBQ. Furthermore, heterologous expression in A. thaliana confirmed SaNOX1 expression only at the root tip, the site of haustorial development. 
Like other respiratory burst oxidase homologues (Rboh) in plants, structural predictions of SaNOX1 indicate all the features required for calcium-regulated ROS production are conserved in this protein. Based on these predictions, as well as its observed regulation by $\mathrm{pBQ}$ concentrations, we suspect that SaNOX1 provides the source of semagenic ROS. Direct support for the redox activity of SaNOX1, however, that may require expression in a heterologous host as knockout/knockdown experiments are currently limited in S. asiatica.

As for SaNOX2 and SaNOX3, while they appear to be N-terminal truncations of these Rboh proteins, they retain all of the features associated with ROS production and may be well expressed in their corresponding tissues. The apparent absence of EF-hand domains for calcium regulation is unusual in plants but is not uncommon in other eukaryotes [46]. The variations in their sequence as well as exon-intron utilization argue against their arising simply from recent gene duplication events. Indeed comparative exon-intron analysis between the eight Rboh proteins from Arabidopsis thaliana confirm distinct exon-intron patterns for several of those proteins as well, although none display truncations like those in SaNOX2 or SaNOX3 [42] [43]. Such unusual truncations may reflect the accelerated rate at which mutations appear to accumulate among parasitic angiosperms, relative to their non-parasitic relatives [47]. These increased rates of mutation may well provide an adaptive advantage to parasites in dealing with the evolution of resistance in hosts.

In addition to their well-established roles in defense, ROS production has also been implicated in plant growth and development including root hair formation and pollen tube growth [31]-[33]. In this context, the redox events associated with semagenesis may not be unique to haustorial organogenesis, but more generally associated with cell-cell signaling and development. Increasing evidence implicates the semagenic quinones as not only regulating haustorial development in the parasitic plants [15], but more broadly in root meristem growth and development. The addition of semagenic quinones impacts development of both root architecture and notably root hair density in A. thaliana and N. tabaccum as well as the production of ROS [15] [48].

Root growth and architecture is sensitive to the density and identity of neighboring roots (self and non-self) [49] [50] and the chemistry exploited by $S$. asiatica in semagenesis could serve a more general quorum sensingtype role in plant roots, controlling morphological development (phenotype) based on their proximal neighbors. In this context, understanding the integration of accumulating $\mathrm{pBQ}$ s via semagenesis in $S$. asiatica may provide greater insight into how plants 'decide' to organize the architecture of their root systems. Indeed, the strigolactones, which were originally discovered as germination stimulants for Striga spp. (Figure 1(a)), have now been shown to function as regulators of branching in both plants and arbuscular mychorizzal fungi [51] [52]. These findings bolster the model that xenognosin-regulated transitions in parasites likely arose from pre-existing regulatory pathways present among non-parasites. Given the tight regulation of these transitions, these systems now serve as valuable model systems for defining the molecular machinery responsible for signal integration, response to environmental inputs, and decision-making in critical developmental commitments. Such information can be used to regulate the "decision making" processes and drive productive/lethal transitions in plants. This information then is critical to reading and controlling the molecular code of plant environmental sensing and adaptation to an ever-changing environmental landscape.

\section{Acknowledgements}

We thank Eric Weeks (Emory Department of Physics) for support with confocal microscopy.

\section{References}

[1] Hillesland, K.L. and Stahl, D.A. (2010) Rapid Evolution of Stability and Productivity at the Origin of a Microbial Mutualism. Proceedings of the National Academy of Sciences of the United States of America, 107, 2124-2129. http://dx.doi.org/10.1073/pnas.0908456107

[2] Kim, D., Kocz, R., Boone, L., Keyes, W.J. and Lynn, D.G. (1998) On Becoming a Parasite: Evaluating the Role of Wall Oxidases in Parasitic Plant Development. Chemistry \& Biology, 5, 103-117. http://dx.doi.org/10.1016/S1074-5521(98)90144-2

[3] Keyes, W.J., Malley, R.C.O., Kim, D. and Lynn, D.G. (2000) Signaling Organogenesis in Parasitic Angiosperms : Xenognosin Generation, Perception and Response. Journal of Plant Growth Regulation, 19, 217-231. http://dx.doi.org/10.1007/s003440000024

[4] Palmer, A.G., Gao, R., Maresh, J., Erbil, W.K. and Lynn, D.G. (2004) Chemical Biology of Multi-Host/Pathogen Interactions: Chemical Perception and Metabolic Complementation. Annual Review of Phytopathology, 42, 439-464. 
http://dx.doi.org/10.1146/annurev.phyto.41.052002.095701

[5] Lynn, D.G. and Chang, M. (1990) Phenolic Signals in Cohabitation: Implications for Plant Development. Annual Reviews of Plant Physiology and Plant Molecular Biology, 41, 497-526. http://dx.doi.org/10.1146/annurev.pp.41.060190.002433

[6] Chang, M. and Lynn, D.G. (1986) The Haustorium and the Chemistry of Host Recognition in Parasitic Angiosperms. Journal of Chemical Ecology, 12, 561-579. http://dx.doi.org/10.1007/BF01020572

[7] Fate, G., Chang, M. and Lynn, D.G. (1990) Control of Germination in Striga asiatica: Chemistry of Spatial Definition. Plant Physiology, 93, 201-207. http://dx.doi.org/10.1104/pp.93.1.201

[8] Kim, D., Kocz, R., Boone, L., Keyes, W.J. and Lynn, D.G. (1998) On Becoming a Parasite: Evaluating the Role of Wall Oxidases in Parasitic Plant Development. Chemistry and Biology, 5, 103-117. http://dx.doi.org/10.1016/S1074-5521(98)90144-2

[9] Keyes, W.J., Palmer, A.G., Erbil, W.K., Taylor, J.V., Apkarian, R.P., Weeks, E.R., et al. (2007) Semagenesis and the Parasitic Angiosperm Striga asiatica. Plant Journal, 51,707-716. http://dx.doi.org/10.1111/j.1365-313X.2007.03171.x

[10] Palmer, A.G., Liu, Y., Adkins, S.M., Zhang, X., Wu, I., Chen, X., et al. (2008) The Molecular Language of Semagenesis. Plant Signaling and Behavior, 3, 560-561. http://dx.doi.org/10.4161/psb.3.8.5703

[11] Worsham, A.D., Moreland, D.E. and Klingman, G.C. (1959) Stimulation of Striga asiatica (Witchweed) Seed Germination by 6-Substituted Purines. Science, 130, 1654-1656. http://dx.doi.org/10.1126/science.130.3389.1654

[12] Dorr, I. (1997) How Striga Parasitizes Its Host: A TEM and SEM Study. Annals of Botany, 79, 463-472. http://dx.doi.org/10.1006/anbo.1996.0385

[13] Smith, C.E., Ruttledge, T., Zeng, Z., O’Malley, R.C. and Lynn, D.G. (1996) A Mechanism for Inducing Plant Development: The Genesis of a Specific Inhibitor. Proceedings of the National Academy of Sciences of the United States of America, 93, 6986-6991. http://dx.doi.org/10.1073/pnas.93.14.6986

[14] O’Malley, R.C. and Lynn, D.G. (2000) Expansin Message Regulation in Parasitic Angiosperms: Marking Time in Development. The Plant Cell, 12, 1455-1465. http://dx.doi.org/10.1105/tpc.12.8.1455

[15] Tomilov, A., Tomilova, N., Shin, D.H., Jamison-McClung, D., Torres, M., Reagan, R., McGray, H., Horning, T., Truong, R., Nava, A.J., Nava, A. and Yoder, J.I. (2006) Chemical Signaling between Plants: Mechanistic Similarities between Allelopathy and Host Plant Recognition by Parasitic ANGIOSPERMS. In: Dicke, M. and Takken, W., Eds., Chemical Ecology: From Genes to Ecosystem, Springer, Berlin, 55-69.

[16] Esfandiari, E., Jin, Z., Abdeen, A., Griffiths, J.S., Western, T.L. and Haughn, G.W. (2013) Identification and Analysis of an Outer-Seed-Coat-Specific Promoter from Arabidopsis thaliana. Plant Molecular Biology, 81, 93-104. http://dx.doi.org/10.1007/s11103-012-9984-0

[17] Tague, B.W. and Mantis, J. (2006) In Planta Agrobacterium-Mediated Transformation by Vacuum Infiltration. In: Salinas, J. and Sanchez-Serrano, J.J., Eds., Arabidopsis Protocols, Humana Press, New York, 215-223. http://dx.doi.org/10.1385/1-59745-003-0:215

[18] Galbraith, E.A., Antonopoulos, D.A. and White, B.A. (2008) Application of Suppressive Subtractive Hybridization to Uncover the Metagenomic Diversity of Environmental Samples. In: Martin, C.C., Ed., Environmental Genomics, Humana Press, New York, 295-334. http://dx.doi.org/10.1007/978-1-59745-548-0_16

[19] Mahalingam, R., Gomez-Buitrago, A., Eckardt, N., Shah, N., Guevara-Garcia, A., Day, P., et al. (2003) Characterizing the Stress/Defense Transcriptome of Arabidopsis. Genome Biology, 4, R20. http://dx.doi.org/10.1186/gb-2003-4-3-r20

[20] Matvienko, M., Wojtowicz, A., Wrobel, R., Jamison, D., Goldwasser, Y. and Yoder, J.I. (2001) Quinone Oxidoreductase Message Levels Are Differentially Regulated in Parasitic and Non-Parasitic Plants Exposed to Allelopathic Quinones. The Plant Journal, 25, 375-387. http://dx.doi.org/10.1046/j.1365-313x.2001.00971.x

[21] Bandaranayake, P.C.G., Filappova, T., Tomilov, A., Tomilova, N.B., Jamison-McClung, D., Ngo, Q., et al. (2010) A Single-Electron Reducing Quinone Oxidoreductase Is Necessary to Induce Haustorium Development in the Root Parasitic Plant Triphysaria. The Plant Cell, 22, 1404-1419. http://dx.doi.org/10.1105/tpc.110.074831

[22] Tomilov, A.A., Tomilova, N.B., Abdallah, I. and Yoder, J.I. (2005) Localized Hormone Fluxes and Early Haustorium Development in the Hemiparasitic Plant Triphysaria versicolor. Plant Physiology, 138, 1469-1480. http://dx.doi.org/10.1104/pp.104.057836

[23] Bao, Y., Kost, B. and Chua, N.H. (2001) Reduced Expression of Alpha-Tubulin Genes in Arabidopsis thaliana Specifically Affects Root Growth and Morphology, Root Hair Development and Root Gravitropism. The Plant Journal, 28, 145-157. http://dx.doi.org/10.1046/j.1365-313X.2001.01142.x

[24] Ursin, V.M., Irvine, J.M., Hiatt, W.R. and Shewmaker, C.K. (1991) Developmental Analysis of Elongation Factor-1 Alpha Expression in Transgenic Tobacco. The Plant Cell, 3, 583-591. http://dx.doi.org/10.1105/tpc.3.6.583

[25] Lin, C.M., Chen, C.T., Lee, H.H. and Lin, J.K. (2002) Prevention of Cellular ROS Damage by Isovitexin and Related 
Flavonoids. Planta Medica, 68, 365-367. http://dx.doi.org/10.1055/s-2002-26753

[26] Bolwell, G.P., Butt, V.S., Davies, D.R. and Zimmerlin, A. (1995) The Origin of the Oxidative Burst in Plants. Free Radical Research, 23, 517-532. http://dx.doi.org/10.3109/10715769509065273

[27] Montillet, J.L., Cacas, J.L., Garnier, L., Montané, M.H., Douki, T., Bessoule, J.J., et al. (2004) The Upstream Oxylipin Profile of Arabidopsis thaliana: A Tool to Scan for Oxidative Stresses. Plant Journal, 40, 439-451. http://dx.doi.org/10.1111/j.1365-313X.2004.02223.x

[28] Järvinen, A., Grigorenko, N., Khomutov, A.R., Hyvönen, M.T., Uimari, A., Vepsäläinen, J., et al. (2005) Metabolic Stability of $\alpha$-Methylated Polyamine Derivatives and Their Use as Substitutes for the Natural Polyamines. The Journal of Biological Chemistry, 280, 6595-6601. http://dx.doi.org/10.1074/jbc.M412788200

[29] Moller, I.M. (2001) PLANT MITOCHONDRIA AND OXIDATIVE STRESS: Electron Transport, NADPH Turnover, and Metabolism of Reactive Oxygen Species. Annual Review of Plant Physiology and Plant Molecular Biology, 52, 561-591. http://dx.doi.org/10.1146/annurev.arplant.52.1.561

[30] Gucciardo, S., Wisniewski, J.P., Brewin, N.J. and Bornemann, S. (2007) A Germin-Like Protein with Superoxide Dismutase Activity in Pea Nodules with High Protein Sequence Identity to a Putative Rhicadhesin Receptor. Journal of Experimental Botany, 58, 1161-1171. http://dx.doi.org/10.1093/jxb/erl282

[31] Foreman, J., Demidchik, V., Bothwell, J.H.F., Mylona, P., Miedema, H., Torres, M.A., et al. (2003) Reactive Oxygen Species Produced by NADPH Oxidase Regulate Plant Cell Growth. Nature, 422, $442-446$. http://dx.doi.org/10.1038/nature01485

[32] Jabs, T., Tschope, M., Colling, C., Hahlbrock, K. and Scheel, D. (1997) Elicitor-Stimulated Ion Fluxes and $\mathrm{O}_{2}^{-}$from the Oxidative Burst Are Essential Components in Triggering Defense Gene Activation and Phytoalexin Synthesis in Parsley. Proceedings of the National Academy of Sciences of the United States of America, 94, 4800-4805. http://dx.doi.org/10.1073/pnas.94.9.4800

[33] Rea, G., de Pinto, M.C., Tavazza, R., Biondi, S., Gobbi, V., Ferrante, P., et al. (2004) Ectopic Expression of Maize Polyamine Oxidase and Pea Copper Amine Oxidase in the Cell Wall of Tobacco Plants. Plant Physiology, 134, 14141426. http://dx.doi.org/10.1104/pp.103.036764

[34] Jaquet, V., Scapozza, L., Clark, R.A., Krause, K.-H. and Lambeth, J.D. (2009) Small-Molecule NOX Inhibitors: ROS-Generating NADPH Oxidases as Therapeutic Targets. Antioxidants \& Redox Signaling, 11, 2535-2552. http://dx.doi.org/10.1089/ars.2009.2585

[35] Abramov, A.Y., Jacobson, J., Wientjes, F., Hothersall, J., Canevari, L. and Duchen, M.R. (2005) Expression and Modulation of an NADPH Oxidase in Mammalian Astrocytes. The Journal of Neuroscience, 25, 9176-9184. http://dx.doi.org/10.1523/JNEUROSCI.1632-05.2005

[36] Das, D.K., Engelman, R.M., Clement, R., Otani, H., Prasad, M.R. and Rao, P.S. (1987) Role of Xanthine Oxidase Inhibitor as Free Radical Scavenger: A Novel Mechanism of Action of Allopurinol and Oxypurinol in Myocardial Salvage. Biochemical and Biophysical Research Communications, 148, 314-319. http://dx.doi.org/10.1016/0006-291X(87)91112-0

[37] Davies, B. and Edwards, S.W. (1989) Inhibition of Myeloperoxidase by Salicylhydroxamic Acid. Biochemical Journal, 258, 801-806. http://dx.doi.org/10.1042/bj2580801

[38] Le Cabec, V. and Maridonneau-Parini, I. (1995) Complete and Reversible Inhibition of NADPH Oxidase in Human Neutrophils by Phenylarsine Oxide at a Step Distal to Membrane Translocation of the Enzyme Subunits. Journal of Biological Chemistry, 270, 2067-2073. http://dx.doi.org/10.1074/jbc.270.5.2067

[39] Matsunaga, T., Kudo, J., Takahashi, K., Dohmen, K., Hayashida, K., Okamura, S., et al. (1996) Rotenone, a Mitochondrial NADH Dehydrogenase Inhibitor, Induces Cell Surface Expression of CD13 and CD38 and Apoptosis in HL60 Cells. Leukemia \& Lymphoma, 20, 487-494. http://dx.doi.org/10.3109/10428199609052434

[40] Pivovarov, A.S. and Egido-Villareal, W. (1995) The Influence of an Inhibitor of Lipoxygenases on the Modulation of the Plasticity of Cholinoreceptors by 15-Hete. Neuroscience and Behavioral Physiology, 25, 483-487. http://dx.doi.org/10.1007/BF02359276

[41] Potocký, M., Jones, M.A., Bezvoda, R., Smirnoff, N. and Žárský, V. (2007) Reactive Oxygen Species Produced by NADPH Oxidase Are Involved in Pollen Tube Growth. New Phytologist, 174, 742-751. http://dx.doi.org/10.1111/j.1469-8137.2007.02042.x

[42] Torres, M.A., Onouchi, H., Hamada, S., Machida, C., Hammond-kosack, K.E. and Jones, J.D.G. (1998) Six Arabidopsis thaliana Homologues of the Human Respiratory Burst Oxidase (gp91 ${ }^{\text {phox }}$ ). The Plant Journal, 14, 365-370. http://dx.doi.org/10.1046/j.1365-313X.1998.00136.x

[43] Yoshioka, H., Numata, N., Nakajima, K., Katou, S., Kawakita, K., Rowland, O., et al. (2003) Nicotiana benthamiana gp $91^{\text {phox }}$ Homologs NbrbohA and NbrbohB Participate in $\mathrm{H}_{2} \mathrm{O}_{2}$ Accumulation and Resistance to Phytophthora infestans. The Plant Cell, 15, 706-718. http://dx.doi.org/10.1105/tpc.008680 
[44] Kuijt, J. (1969) The Biology of Parasitic Flowering Plants. University of California Press, Berkeley.

[45] Barkman, T.J., McNeal, J.R., Lim, S.-H., Coat, G., Croom, H.B., Young, N.D., et al. (2007) Mitochondrial DNA Suggests at Least 11 Origins of Parasitism in Angiosperms and Reveals Genomic Chimerism in Parasitic Plants. BMC Evolutionary Biology, 7, 248. http://dx.doi.org/10.1186/1471-2148-7-248

[46] Lambeth, J.D. (2004) NOX Enzymes and the Biology of Reactive Oxygen. Nature Reviews Immunology, 4, $181-189$. http://dx.doi.org/10.1038/nri1312

[47] Bromham, L., Cowman, P.F. and Lanfear, R. (2013) Parasitic Plants Have Increased Rates of Molecular Evolution across All Three Genomes. BMC Evolutionary Biology, 13, 126. http://dx.doi.org/10.1186/1471-2148-13-126

[48] Palmer, A.G., Chen, M.C., Kinger, N.P. and Lynn, D.G. (2009) Parasitic Angiosperms, Semagenesis and General Strategies for Plant-Plant Signaling in the Rhizosphere. Pest Management Science, 65, 512-519. http://dx.doi.org/10.1002/ps.1717

[49] Bhatt, M.V., Khandelwal, A. and Dudley, S.A. (2011) Kin Recognition, Not Competitive Interactions, Predicts Root Allocation in Young Cakile edentula Seedling Pairs. New Phytologist, 189, 1135-1142. http://dx.doi.org/10.1111/j.1469-8137.2010.03548.x

[50] Casper, B.B. and Jackson, R.B. (1997) Plant Competition Underground. Annual Review of Ecology and Systematics, 28, 545-570. http://dx.doi.org/10.1146/annurev.ecolsys.28.1.545

[51] Besserer, A., Puech-Pagès, V., Kiefer, P., Gomez-Roldan, V., Jauneau, A., Roy, S., et al. (2006) Strigolactones Stimulate Arbuscular Mycorrhizal Fungi by Activating Mitochondria. PLoS Biology, 4, 1239-1247. http://dx.doi.org/10.1371/journal.pbio.0040226

[52] Dun, E.A., Brewer, P.B. and Beveridge, C.A. (2009) Strigolactones: Discovery of the Elusive Shoot Branching Hormone. Trends in Plant Science, 14, 364-372. http://dx.doi.org/10.1016/i.tplants.2009.04.003 


\section{Supplemental Information}

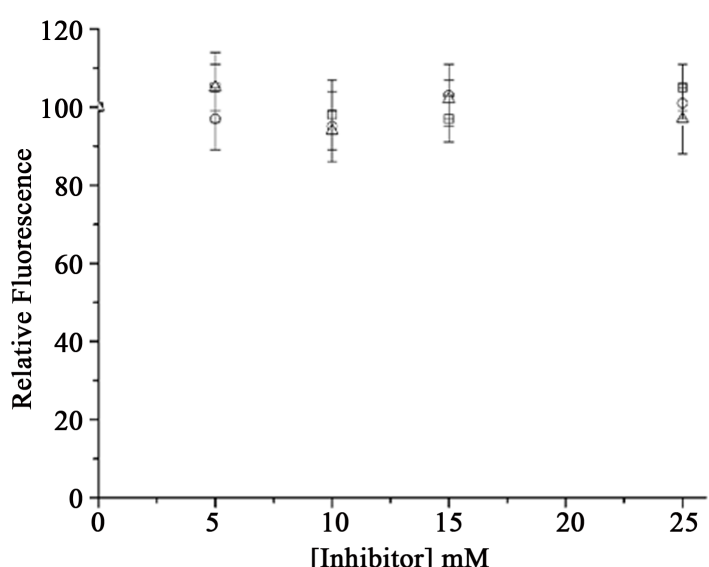

(a)

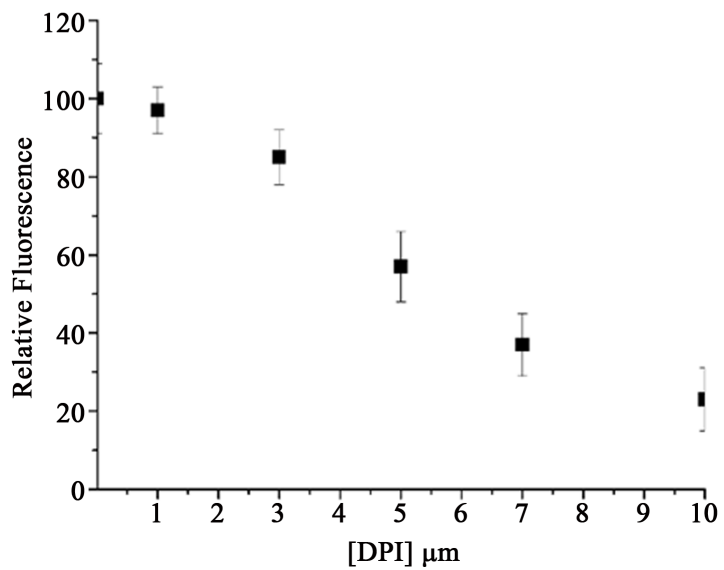

(c)

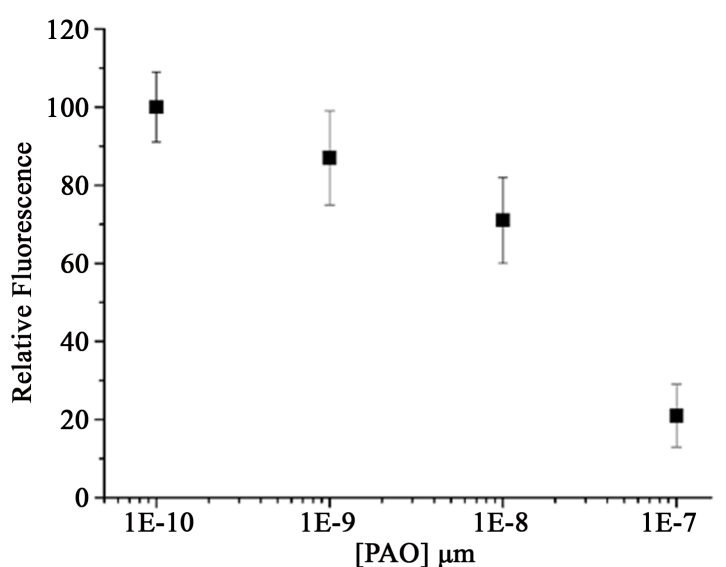

(b)

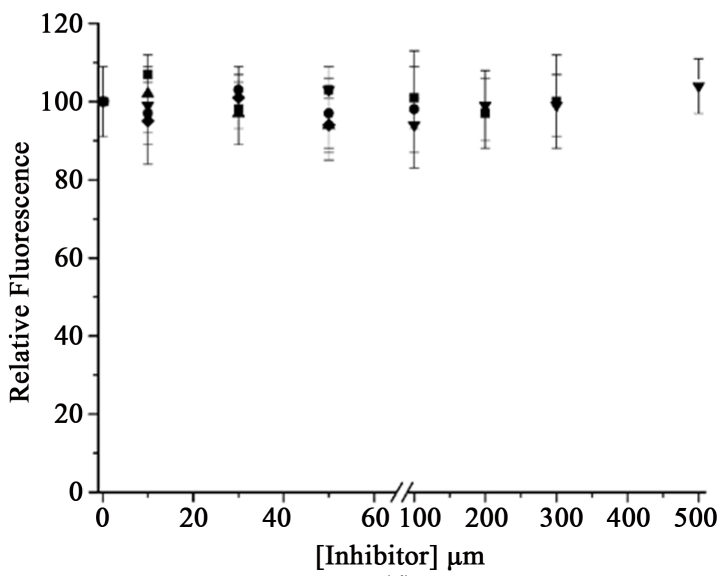

(d)

Figure S1. Effect of ROS inhibitors on CM- $\mathrm{H}_{2}$ DCFDA assay. Two day old seedlings of Striga asiatica are incubated with the indicated concentration of inhibitor for 2 hours then loaded with $10 \mu \mathrm{M} \mathrm{CM}-\mathrm{H}_{2} \mathrm{DCFDA}$ for 5 minutes and imaged for ROS production (See Methods). The ROS source for each inhibitor is indicated in parentheses behind each inhibitor. (a) $\square$ Salicylhydroxamic acid (peroxidases) [37], o AEBCF (Animal not plant NOX proteins), $\triangle$ Apocynin (Animal not plant NOX) [35]; (b) Phenylarsineoxide (PAO) (NOX) [38]; (c) Diphenyleneiodonium (DPI) (NOX) [41]; (d) ■ Oxypurinol (Xanthine oxidases) [36], • Allopurinol (Xanthine oxidases) [36], $\boldsymbol{\Delta}$ Rotenone (Mitochondrial complex I) [39], $\boldsymbol{\nabla}$ MDL 72,527 (polyamine oxidase) [33], Nordihydroguaiartic acid (lipoxygenase) [40]. Fluorescence intensity expressed relative to Striga seedlings treated with $\mathrm{CM}-\mathrm{H}_{2}$ DCFDA only (set at 100). Results are the average of three trials with error equal to $+/-$ the standard deviation of the mean. 


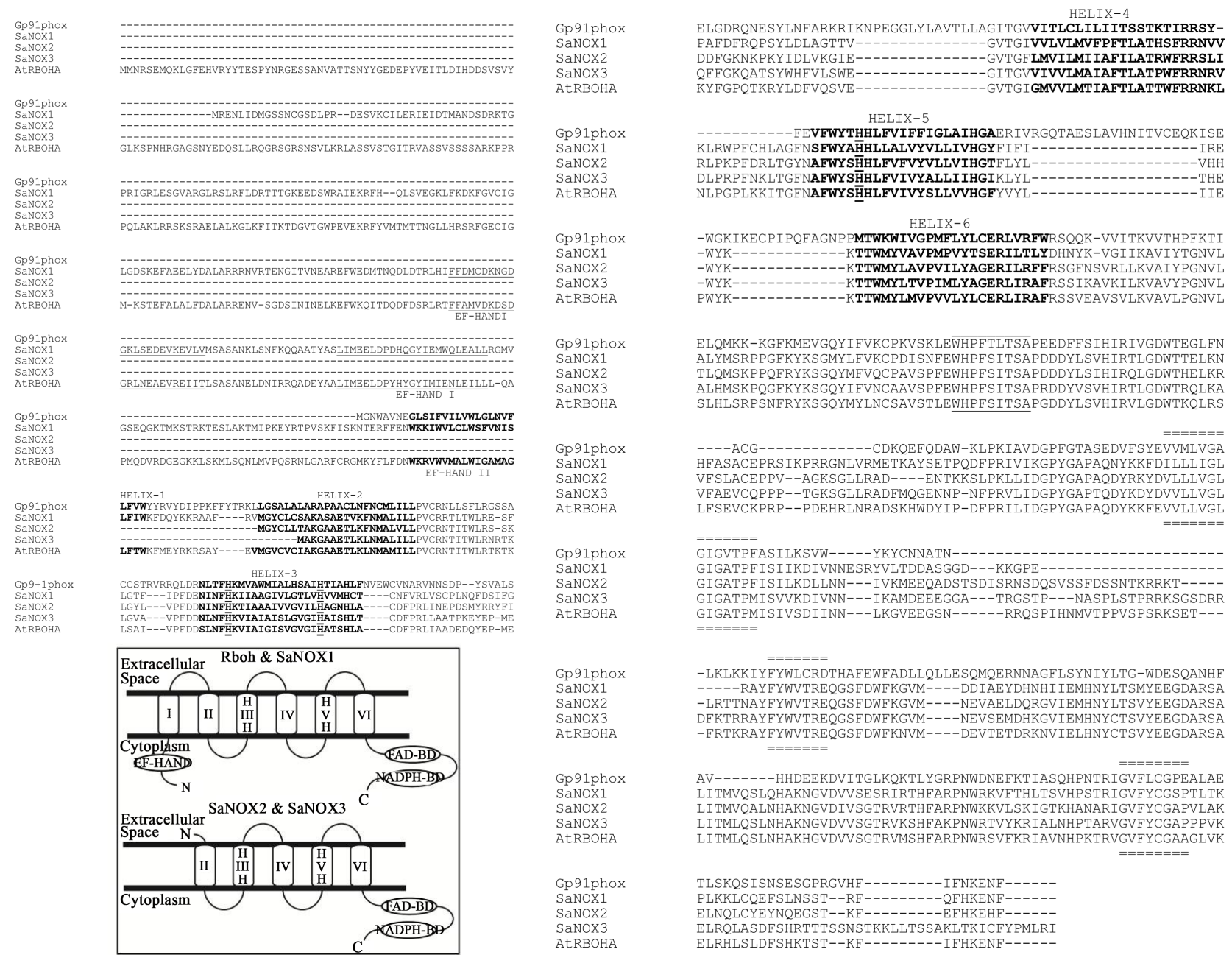

Figure S2. Proposed structure of SaNOX1-3 based on BLAST analysis, CLUSTALW alignments, and published literature on the structure of gp91phox and the Arabidopsis thaliana respiratory burst oxidase A (Rboh A). Both of these proteins produce superoxide anions but only Rboh $\mathrm{A}$ is regulated be calcium due to the presence of the $\mathrm{Ca}^{2+}$-binding EF-hand domains which are also conserved in SaNOX1 (underlined) but not SaNOX 2 or 3. In addition the first transmembrane helix found in SaNOX1, Rboh A, and gp91phox (H1 and bold text) is absent in SaNOX2 and 3. Near the C-terminus of the proteins are the highly conserved FAD and NADPH binding domains (BD) indicated by the single line or double lines respectively. 


\begin{tabular}{|c|c|c|c|c|}
\hline SaNOX1 & $\begin{array}{c}\text { Genomic } \\
\text { coordinates }\end{array}$ & $\begin{array}{c}\text { mRNA } \\
\text { coordinates }\end{array}$ & $\begin{array}{l}\text { Exon } \\
\text { Length }\end{array}$ & $\%$ Identity \\
\hline Exon 1 & $1-304$ & $1-304$ & 304 & $99.70 \%$ \\
\hline Exon 2 & $403-565$ & $305-467$ & 163 & $100.00 \%$ \\
\hline Exon 3 & $681-729$ & $468-516$ & 49 & $100.00 \%$ \\
\hline Exon 4 & $855-968$ & $517-630$ & 114 & $100.00 \%$ \\
\hline Exon 5 & $1047-1860$ & $631-1443$ & 813 & $99.40 \%$ \\
\hline Exon 6 & $1943-2035$ & $1444-1536$ & 93 & $98.90 \%$ \\
\hline Exon 7 & $2120-2235$ & $1537-1652$ & 116 & $99.10 \%$ \\
\hline Exon 8 & $2404-2507$ & $1653-1756$ & 104 & $100.00 \%$ \\
\hline Exon 9 & $2618-2699$ & $1757-1838$ & 82 & $100.00 \%$ \\
\hline Exon 10 & $2810-2957$ & $1839-1986$ & 148 & $100.00 \%$ \\
\hline Exon 11 & 3058-3192 & $1987-2121$ & 135 & $100.00 \%$ \\
\hline Exon 12 & $3293-3610$ & 2122-2439 & 318 & $100.00 \%$ \\
\hline \multicolumn{5}{|l|}{ SaNOX2 } \\
\hline & $\begin{array}{l}\text { Genomic } \\
\text { coordinates }\end{array}$ & $\begin{array}{c}\text { mRNA } \\
\text { coordinates }\end{array}$ & $\begin{array}{l}\text { Exon } \\
\text { Length }\end{array}$ & $\%$ Identity \\
\hline Exon 1 & $1-546$ & $1-546$ & 546 & $100.00 \%$ \\
\hline Exon 2 & $654-749$ & $547-642$ & 96 & $100.00 \%$ \\
\hline Exon 3 & $849-964$ & $643-758$ & 116 & $100.00 \%$ \\
\hline Exon 4 & $1112-1279$ & $759-926$ & 168 & $100.00 \%$ \\
\hline Exon 5 & $1362-1521$ & $927-1086$ & 160 & $100.00 \%$ \\
\hline Exon 6 & $1627-1809$ & $1087-1269$ & 183 & $100.00 \%$ \\
\hline Exon 7 & $1895-2102$ & $1270-1477$ & 208 & $100.00 \%$ \\
\hline Exon 8 & 2193-2302 & $1478-1587$ & 110 & $100.00 \%$ \\
\hline \multicolumn{5}{|l|}{ SaNOX3 } \\
\hline & $\begin{array}{l}\text { Genomic } \\
\text { coordinates }\end{array}$ & $\begin{array}{c}\text { mRNA } \\
\text { coordinates }\end{array}$ & $\begin{array}{l}\text { Exon } \\
\text { Length }\end{array}$ & $\%$ Identity \\
\hline Exon 1 & $1-528$ & $1-528$ & 528 & $100.00 \%$ \\
\hline Exon 2 & $621-716$ & $529-624$ & 96 & $99.00 \%$ \\
\hline Exon 3 & $908-1023$ & $625-740$ & 116 & $100.00 \%$ \\
\hline Exon 4 & $1244-1420$ & $741-917$ & 177 & $100.00 \%$ \\
\hline Exon 5 & $2200-2911$ & $918-1629$ & 712 & $100.00 \%$ \\
\hline
\end{tabular}

Figure S3. Results of SPIDEY analysis using mRNA and genomic sequences for: SaNOX1, 2, and 3 respectively (http://www.ncbi.nlm.nih.gov/IEB/Research/Ostell/Spidey/).

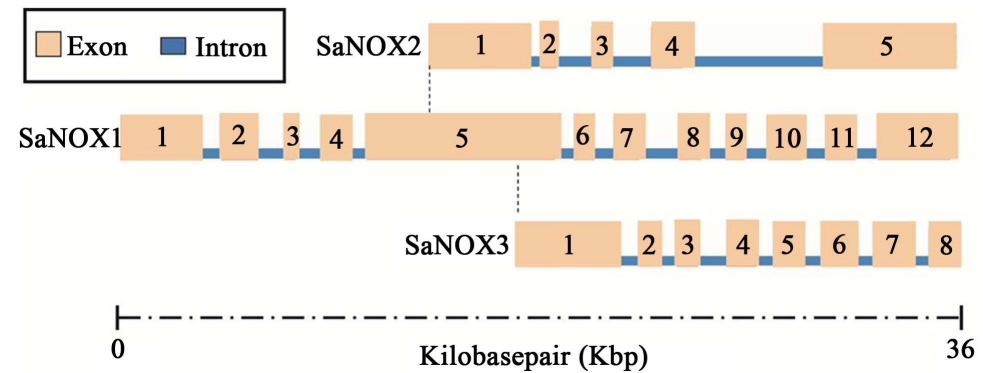

Figure S4. Exon-intron analysis of SaNOX1, 2 and 3. Genomic sequences of SaNOX1-3 are organized by exons and introns, based on the SPIDEY analysis above (See Supplementary Table 1). The first exons of SaNOX2 and 3 are positioned to reflect the exon of SaNOX1 to which they show the greatest similarity (based on CLUSTALW analysis). Position is indicated by vertical dashed lines Sequences are drawn to scale. 


\section{Submit or recommend next manuscript to SCIRP and we will provide best service for you:}

Accepting pre-submission inquiries through Email, Facebook, Linkedin, Twitter, etc A wide selection of journals (inclusive of 9 subjects, more than 200 journals)

Providing a 24-hour high-quality service

User-friendly online submission system

Fair and swift peer-review system

Efficient typesetting and proofreading procedure

Display of the result of downloads and visits, as well as the number of cited articles

Maximum dissemination of your research work

Submit your manuscript at: http://papersubmission.scirp.org/ 